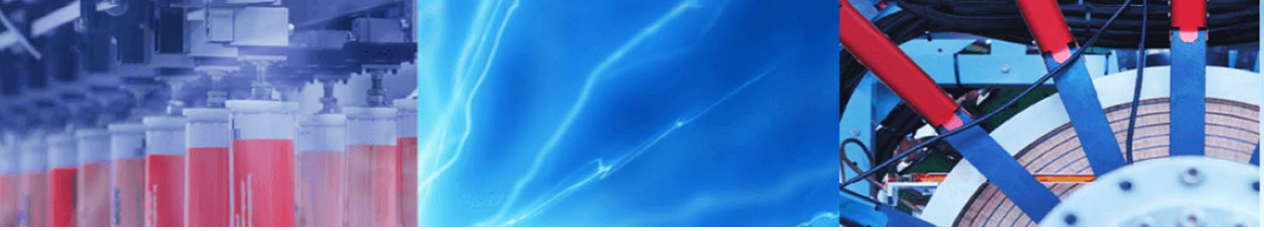

Research Article

\title{
Impact of MTA blend \% in melt spinning process and polyester properties
}

\author{
Puli Nageswar Rao' - G. K. Sabavath ${ }^{2}$. S. N. Paul ${ }^{3}$
}

Received: 3 August 2020 / Accepted: 28 December 2020 / Published online: 23 January 2021

(c) The Author(s) $2021 \quad$ OPEN

\begin{abstract}
In Polyethylene terephthalate (PET) processing the raw materials are purified terephthalic acid (PTA), moderately purified terephthalic acid (MTA), monoehalene glycol (MEG). The processing of PTA is very difficult and costly. For reducing PTA percent we are using different percentages of MTA blend in PET processing. MTA affected the properties of polyester and melt spinning process. The properties such as elongation, tenacity, molecular chain length, b-color and IV, thermal properties, \% carboxyl groups will change with MTA percentage. MTA percentage also affects fiber breakage percentage $s$, the melting point of PET. FTIR results show a change in chemical composition. Particle size, 4-CBA content of MTA affects the properties of the fiber.
\end{abstract}

Keywords Polyethylene terephthalate $\cdot$ Purified terephthalic acid $\cdot$ Medium purified terephthalic acid · Tenacity · Denier

\section{Introduction}

Polyethylene terephthalate (PET) is an outstanding barrier material, it also a thermoplastic polymer resin of the polyester family. PET is widely used to made plastic bottles for soft drinks and its film is frequently used in tape applications because it has extraordinary mechanical strength properties. PET fibers are the most widely produced synthetically organic fibers and more than $60 \%$ of PET production is for synthetic fibers. PET fibers are mainly used for both traditional textile purposes and progressively for industrial applications. These applications are rapidly increasing later; mainly these cables find usage in mooring ropes for boats, ships. These cables consist of many millions of fine synthetic fibers and these have breaking loads of up to two thousand tons [1,2].

In the creation of most polyester applications, the purified terephthalic acid (PTA) development initiated the extensive replacement of dimethyl terephthalate (DMT [3].
Purified terephthalic acid is very cheaper, easier to transport, and easier to handle than DMT, and which allows for faster reaction times than DMT, turn out to be the raw material of choice in most new polyethylene terephthalate based plants and affected a revamping of already existing plants $[3,4]$. A quit recent improvement in terephthalic acid (TA) procedure technology is the most availability of so-called medium quality terephthalic acid, variously known as EPTA, QTA and MTA [4, 5]. MTA is now production inroads in the polyester markets. Eastman and Mitsubishi Chemical are offering their own proprietary medium quality terephthalic acid process without limitations, and offering their technology EPTA and QTA (qualified terephthalic acid) for license respectively [4]. In addition, Sam Nam in Korea producers is marketing QTA for all polyester applications, including bottle, film and fiber. In Asian countries, Indo Rama Synthetics (I) Ltd introduce MTA blend in polyester fibers. MTA production costs are lower than of PTA, with this cost advantage (discount $\$ 20-\$ 30$ per ton) MTA

Puli Nageswar Rao, nageswarapuli@gmail.com | 'Department of S\&H, St. Martin's Engineering College, Secunderabad 500100, India. ${ }^{2}$ Department of Applied Physics, CMR Engineering College, Hyderabad, India. ${ }^{3}$ Department of Metallurgy and Materials Engineering, VNIT, Nagpur, India. 
may change the margin structure and price of polyester products, and competitiveness [5]. This can have so much impact on polyester producers interested in licensing and back-integrating into terephthalic acid. No specific study/ information available on the use of MTA/QTA in POY / PSF production and about downstream product performance. This study discussed the change in the properties of polyester with the MTA blend.

\subsection{PET processing}

PET processing is two routes one is the DMT route [3], another one is the PTA route [6]. The PTA route, which is easier to handle, transport and cheaper, and allows for very quick reaction times than the DMT route. That's why the PTA route is preferable in industrial applications [6-11]. In the PTA route, mono ethylene glycol and purified terephthalic acid (PTA), and moderately purified terephthalic acid (MTA) are used as raw materials to make PET. Impurity levels of PTA and MTA are listed in Table 1. Here

Table 1 Impurity levels of PTA and MTA [5]

\begin{tabular}{llll}
\hline Specification & Unit & PTA & MTA \\
\hline Acidity & mg KOH/gm & 675 & 675 \\
Moisture & wt\% & $0.05-0.12$ & $0.01-0.02$ \\
4-CBA & ppm wt & $10-25$ & $170-300$ \\
Color & L, \% & $98.7-99.1$ & $97.5-99$ \\
& B & $0.8-1.5$ & $2-3$ \\
p-toluic acid & ppm wt & $60-200$ & $10-20$ \\
Metals, ttl & ppm wt & $2-10$ & 5 \\
Benzoic acid & ppm wt & 30 max & $20-50$ \\
Acetic acid & ppm wt & Trace & $400-800$ \\
\hline
\end{tabular}

MTA mixed with different percentages are 0 to $25 \%$ with the step of $5 \%$. The main steps involved in PET processing (shown in Fig. 1a) are first one raw material preparation in this raw material continuously fed together with the catalyst solution into the paste preparation vessel. In the paste preparation vessel, a chemical reaction does not take place. Second one esterification or transesterification, in this step the esterification is carried out in two reactors. The paste is transferred from the paste preparation vessel into the first esterification reactor, where the reaction proceeds to more than $90 \%$ conversion. In the second reactor, the conversion reaches more than $96 \%$ conversion. Third step is pre polycondensation, the prepolycondensation is carried out in the prepolycondensation reactor, in this the esterification degree increases to more than $99 \%$, and the chain length of the polymer increases. The final step is polycondensation, in this step, the polycondensate is transferred into the disc ring reactor, which functions as the main polycondensation stage. To start the polycondensation reaction, antimony is used as a catalyst. The product from the esterification step is then sent to the pre polycondensation unit where the reaction takes place under a vacuum. The pre-poly condensation product is served to the final polycondensation reactor which controls under vacuum and amplified temperature; after that, the polyester melt is managed into different forms like fibers, chips, filaments, etc....

Melted polymer is transported to spinning blocks under pressure (100-200 bars) through metering pumps. Then the polymer melt forced through a fine filter. Filtration of PET molten polymer before it enters into the spinneret further homogenizes melt; Filtration removes solid impurities like semisolid degraded gel, any metal pieces and also eliminates gaseous bubbles. Molten polymer extruded (a)

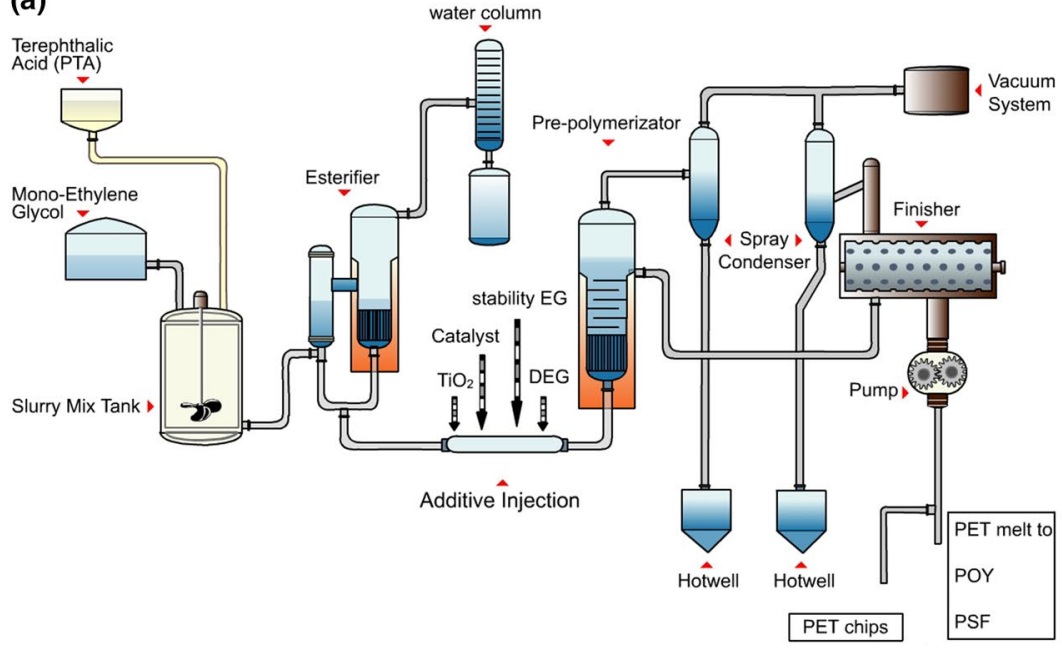

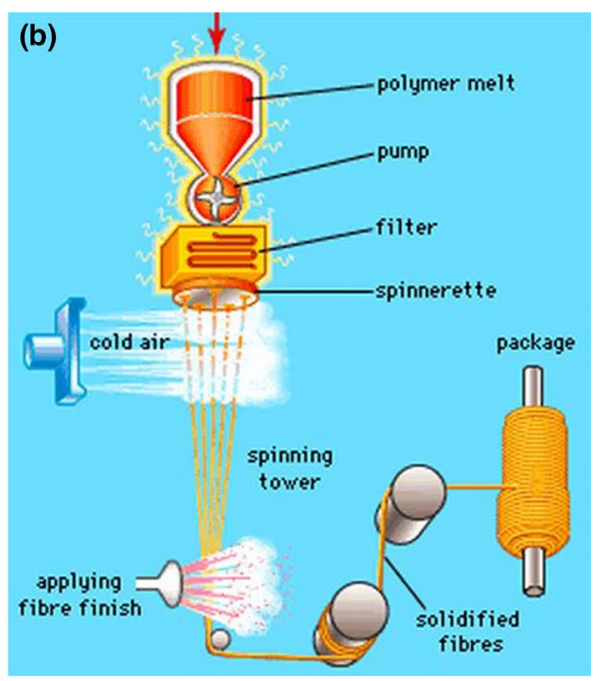

Fig. 1 a Schematic diagram of PET processing, $\mathbf{b}$ Melt spinning process 
from a spinneret stretch. Stretching of the fiber in both solid and molten states provides for the alignment of the polymer chains along the fiber axis and solidifies between a spinneret and take-up in the melt spinning. After leaving the spinneret, molten filaments are cooled (quenched) and solidified by a laminar and uniformly controlled and conditioned airflow. A quench air enhances the solidification of fiber or filament and it helps to make uniform fiber/filaments. PET process in the melt spinning method is shown in Fig. $1 \mathrm{~b}$.

In the melt spinning process, some required processing variables are spinneret diameter should be 3 times more than polymer particle size (diameter). The tensile stress on the melt stream must never exceed the tensile strength of the filament. So take up velocity should not exceed the spinning speed [6]. The molecular weight is generally relatively low $(16,000-19000 \mathrm{~g} / \mathrm{mol})$ in the case of polymer to be used as a fiber. LRV (laboratory relative viscosity) increases as polymer chain length grows as well as the molecular weight of the polymer increases. Resistance to the flow of polymer also increases. Oligomers and polymers are heated more than $320^{\circ} \mathrm{C}$, become black solid-like, non-pourable residue. When heated for more days ( $>4$ days at $280^{\circ} \mathrm{C}$ or $>2.6$ days at $300^{\circ} \mathrm{C}$ ) polymer or oligomer starts degradation. Finally, Cooling conditions also may impact the properties of polyester fiber.

\section{Results and discussions}

\subsection{Chemical analysis}

In order to identify the chemical constituents and to quantify the same, FTIR (Fourier Transform Infra-Red Spectrophotometer) analysis for Polymer samples having $100 \% \mathrm{v}$ PTA and at different MTA blend ratio. FTIR graphs were shown in Fig. 2 and FTIR study reveals the following findings listed in Table 2.

There are known functional groups such as - $\mathrm{OH}$ group (3300-3800)/cm, -COOH group-(1700-1725), Carbonyl group (970-1250)/cm, Wave No (1500-1520)/cm indicates ring structure of $C=C$, Wave No (1700-1725)/cm indicates $\mathrm{COOH}$ group $[12,13]$ concentration of this fraction has been found to increase with the increase in MTA blend \%.

In addition polycondensation itself, even in the absence of oxygen certain thermal-induced degradation of PET melt always takes place. This degradation reaction catalyzed by metal ions, which causes chain breaks. Carboxyl end groups and vinyl ester are formed due to these chain breaks. These vinyl ester end groups can react with the hydroxyl end group of another polymer chain and acetaldehyde is formed as a by-product. The total effect of this side reaction is the substitution of hydroxyl end groups by carboxyl end groups and the formation of an equivalent quantity of acetaldehyde. The thermal induced degradation depends on the residence time (linear correlation) and temperature (exponential correlation) of the polymer. As acetaldehyde is formed during the entire process, it is found in all vapor systems and must be removed, because of its high vapor pressure and relatively low explosion limits. Acetaldehyde will be washed out in an off-gas scrubber $[14,15]$.

The concentration of $\mathrm{COOH}$ groups in the final product is an indicator of the thermal degradation of the polymer. Because it is not possible to distinguish between $\mathrm{COOH}$ groups from non-esterified acid and those arising from thermal degradation, an assessment of polymer quality must be carried out.

This results show increasing the MTA percentage $\mathrm{COOH}$ group also increases because with increasing MTA $\%$ the content of metal particles also increases. These metal ions catalyzed the above reaction. The analysis shows increasing MTA blend \% degradation of polymer increases.

\subsection{Thermal study}

The samples (fibers) of PET are prepared with different MTA were prepared by the method of melt spinning process intrinsic viscosity of these fibers were 0.628 . DSC curves were recorded on a STAR ${ }^{e}$ SW 9.20 DSC. The sample weighs about $3.5 \mathrm{~g}$. the fibers were cut into fine grains, then were put into aluminum pans. An empty aluminum pan was used as reference material. Pure nitrogen is used as furnace atmosphere. The pans were put into the Furnace, DSC curves from ambient temperature to $20^{\circ} \mathrm{C}$ above the melting point measured at a heating rate of $10^{\circ} \mathrm{C} / \mathrm{min}$. DCS curves were obtained at a heating rate of $10^{\circ} \mathrm{C} / \mathrm{min}$.

After reaching $300^{\circ} \mathrm{C}$, the pan was rapidly cooled to ambient temperature $\left(30^{\circ} \mathrm{C}\right)$. melting behavior of polymer depends on the specimen history and particular upon the rate at which the specimen is heated [16]. The melting behavior also depends upon the rate at which the specimen is heated. For eliminating cooling history differences, the thermal scan of the samples was carried out again. DSC results are shown in Figs. 3 and 4.

In Fig. 5, 'M.P1' is a melting point at the first scan;'M.P2' is a melting point repeated scan of the same sample these values are listed in Table 3. The result shows that melting point/ heat of enthalpy and \% crystallinity has no significant influence with the increase of MTA blend against $100 \%$ PTA sample. The melting point is ranging between 254 and $256.2^{\circ} \mathrm{C}$ with no significant trend with an increase of MTA blend\%. It also shows the melting point also depends on the cooling history of the sample. 


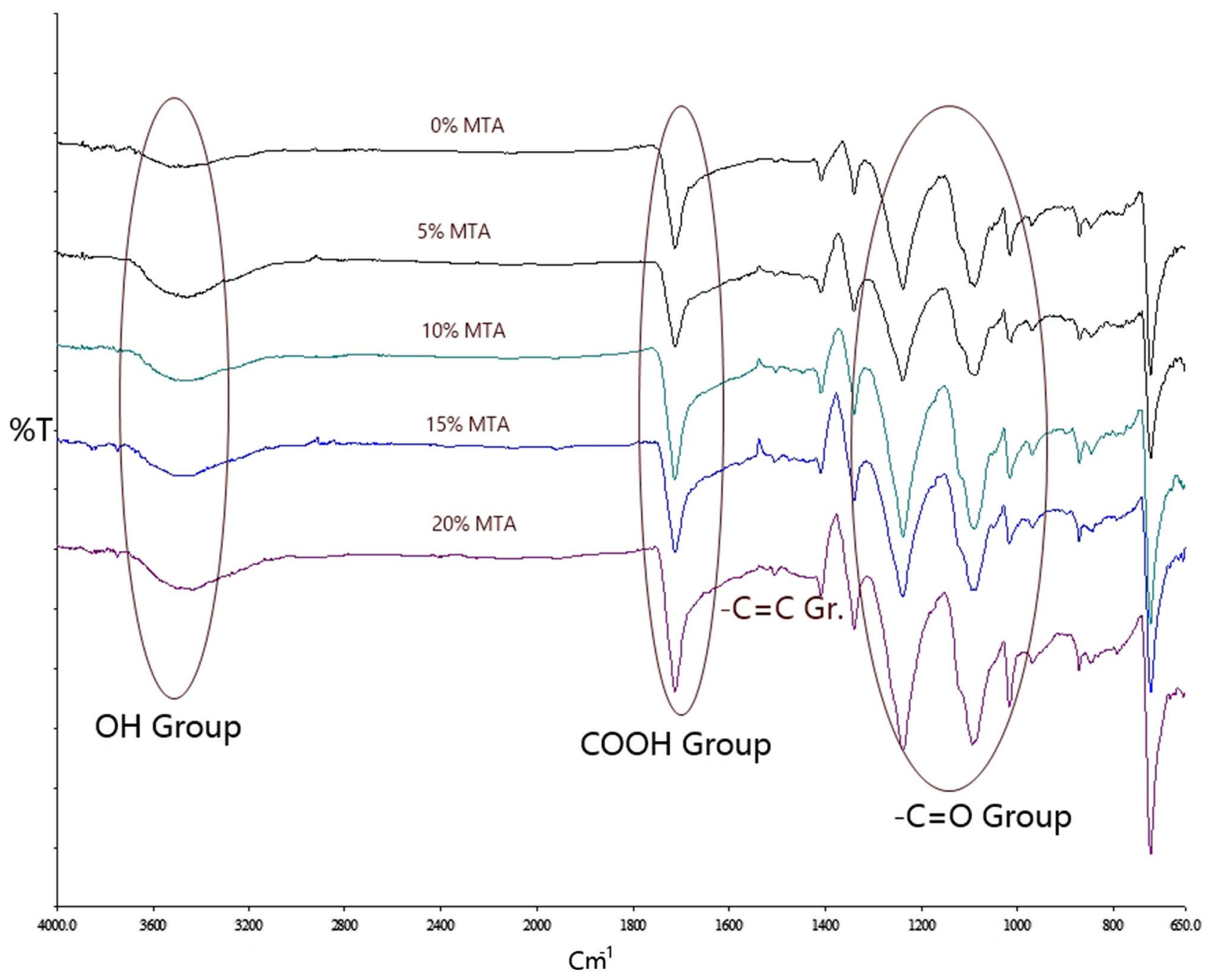

Fig. 2 FTIR spectrum of PET fibers with different MTA\%

Table 2 transmissions of particular wave numbers of polyester with different MTA\%

\begin{tabular}{lllllll}
\hline Wave No & MTA 0\% & MTA 5\% & MTA10\% & MTA 11\% & MTA 20\% & MTA 25\% \\
\hline \multirow{2}{*}{1712} & $\%$ T & \%T & \%T & \%T & $\%$ T & $\%$ T \\
\hline
\end{tabular}

\subsection{Polymer properties and performance analysis}

\subsection{1 b Color and Process Breaks in POY:}

Effect of MTA blend ratio on polymer (POY) color and process breaks were studied and results are shown in Table 4.

With an increase in MTA Blend \%, there is a slight increase in Polymer ' $b$ ' color because 4-CBA and metal content increases with increasing MTA blend \%.

According to a so many technology producer and holder, 4-CBA below 500 ppm levels does not act as a discoloration agent $[18,19]$, but slightly it was a host of additional impurities like conjugated polynuclear organics, and these are co-produced with 4-CBA; and those levels are associated with the 4-CBA content in terephthalic acid, this may cause yellowing [19]. Eastman Chemical patent identifies one more reason for discoloration is fluorenones [6]. Fluorenones that exist in terephthalic acid are mostly dicarboxy fluorenones with a very small amount of tri and mono carboxyfluorenones di-carboxybipheny. Di-carboxybenzophenone and dicarboxybenzil, are also existing. So, these all contaminations are hydrogenated to colorless materials. 


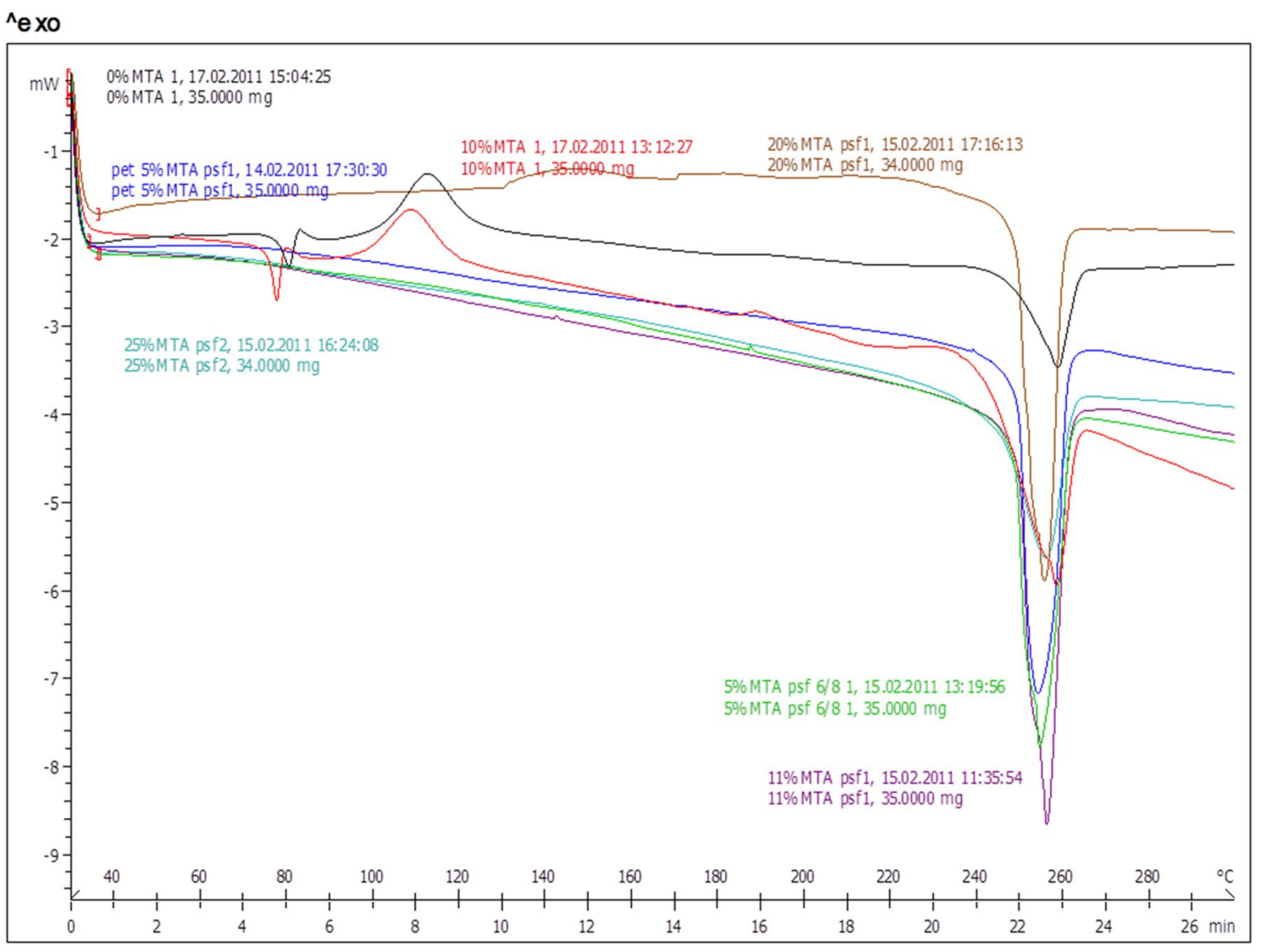

Lab: METTLER

STAR SW 9.20

Fig. 3 DSC curves of different MTA blend PET samples

A color-b value is lower usually far better and it indicates that less yellow) [17]. For PTA, color-b value is less compare to color-b value of MTA.

There is a slight rise in process break, higher process break ending higher waste and lower full packages. The reasons for higher breaks with MTA could be higher concentrations of 4-CBA which act as a chain terminator as well as a branching agent. 4-CBA limit chain growth and molecular mass pileup, and it also cap the polyester chain in the polymerization process.

\subsubsection{Carboxylic $\mathrm{COOH}$ group}

MTA has a low Medium practical size and it causes an impact on PTA/MEG slurry Viscosity (higher) and it also impacts Mole Ratio.

MTA Particle Size is low as compared to PTA and it requires less temperature to react hence to maintain the same Carboxylic end group esterified temperature requires (shown in Table 5) to be reduced with an increase in MTA blend\%. Metal content also acts as a catalyst to promote the reaction to lower temperatures $[2,20]$.

\subsubsection{Intrinsic viscosity}

It has been observed that with a $10-20 \%$ MTA blend as compared with $100 \%$ PTA, the variability of intrinsic viscosity (I.V) of Polymer is slightly reduced.

Reasons for high variability may be due to higher 4-CBA which has a tendency to cap the Polymer chain and hence stopping the chain build up [6].

The thermal and oxygen-induced degradation of PET generates, In addition, polycondensation itself, even in the absence of oxygen certain thermal-induced degradation of PET polymer melt always takes place. This reaction catalyzed by 'metal ions', it causes chain breaks and as a result carboxyl and vinyl ester end groups. Due to the degradation reaction, the viscosity of the polymer decreases considerably. In order to maintain I.V process optimization and control are required.

\subsubsection{Tensile properties}

In order to understand the effect of MTA on PET properties, a study of average PET properties in terms of Draw Force, Elongation and Tenacity of various PET products was 


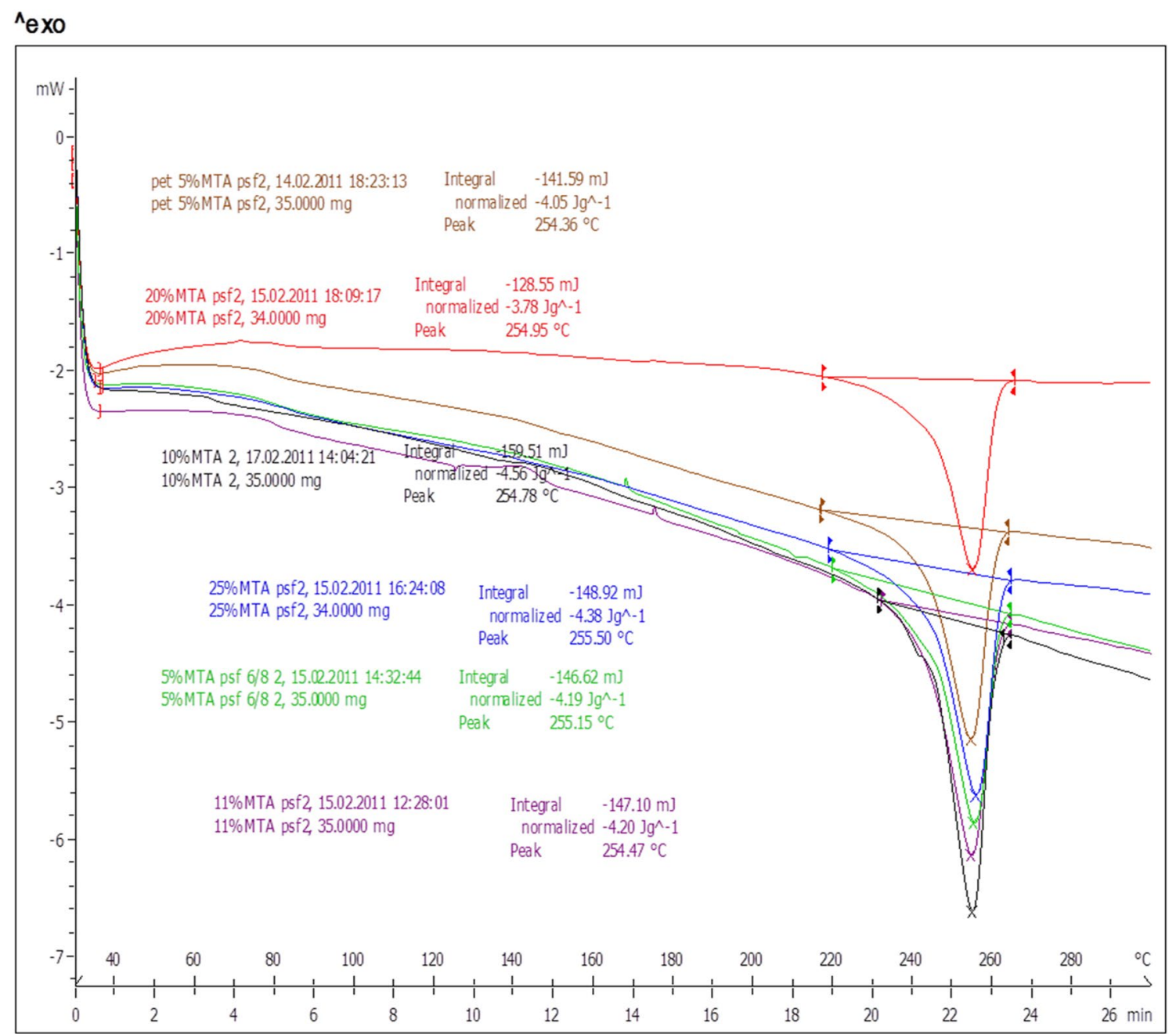

Lab: METTLER

STAR $^{\mathrm{e}} \mathrm{SW} 9.20$

Fig. 4 DSC curves of different MTA blend PET samples second scanning

Fig. 5 Dependence of the melting point with different MTA\% blend PET samples

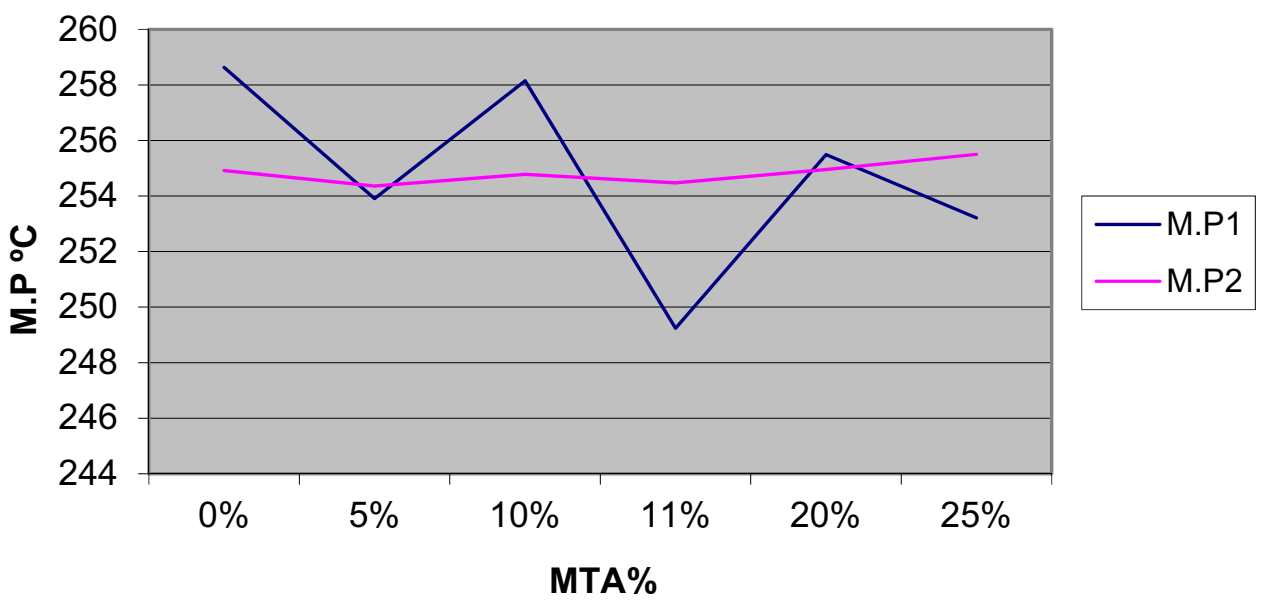


Table 3 DSC results of different MTA\% blend PET samples

\begin{tabular}{lllll}
\hline MTA blend\% & M.P1 & M.P2 & Enthalpy $(\Delta \mathrm{H})$ & Crystallinity $(\%)$ \\
\hline $0 \%$ & 258.63 & 254.92 & 54.2 & 40.1 \\
$5 \%$ & 253.91 & 254.36 & 50.0 & 37.2 \\
$10 \%$ & 258.15 & 254.78 & 50.4 & 37.5 \\
$11 \%$ & 249.24 & 254.47 & 50.5 & 37.7 \\
$20 \%$ & 255.49 & 254.95 & 50.6 & 39.7 \\
$25 \%$ & 253.21 & 255.5 & 53.6 & 39.7 \\
\hline
\end{tabular}

Table 4 'b' color [17] and process breaks with MTA blend

\begin{tabular}{|c|c|c|c|c|}
\hline \multicolumn{2}{|c|}{ Blend ratio } & \multirow{2}{*}{$\begin{array}{l}\text { Average "b" } \\
\text { color }\end{array}$} & \multicolumn{2}{|c|}{ Average breaks/Ton } \\
\hline PTA & MTA & & Total & Process \\
\hline 100 & Nil & 0.96 & 1.26 & 0.58 \\
\hline 95 & 5 & 1.19 & 1.30 & 0.68 \\
\hline 90 & 10 & 1.23 & 1.24 & 0.65 \\
\hline 85 & 15 & 1.38 & 1.28 & 0.62 \\
\hline 80 & 20 & 1.26 & 1.13 & 0.63 \\
\hline
\end{tabular}

carried out for $100 \%$ PTA vesrsus MTA blend are shown in Figs. 6, 7 and 8. Variation of Draw Force, Elongation and Tenacity of PET fibers with MTA blend is listed in Table 6.

The draw is a force that requires drawing the yarn or fiber in the melt spinning process without generating too many filament breaks. Draw is a force of the fibers is calculated using Dynafil M draw force tester. Wrap Reel is used to checking Denier/Count of Yarn. This Yarn Testing Instrument is used to accurately determine count and strength of the various yarns and fibers.

Elongation and Tenacity of fiber or fiber using statmat ME tensile tester, test speed $300 \mathrm{~mm} / \mathrm{min}$. test length of POY is $150 \mathrm{~mm}$. pretensions is $0.15 \mathrm{cN} /$ tex or $1.33 \mathrm{~g} / \mathrm{d}$. Tensile testers using a range of sensitive load cells are used for determining breaking load and load elongation curve of yarn. The yarn is held between two jaws with the upper jaw connected to the load cell and the lower jaw traversed downwards at a constant rate of the traverse. Insertion of a new specimen into the clamps and clamping of the specimen at a pre-determined tension are done automatically. Automatic package changers (with up to 20 packages) are also provided with the tester so that after a prescribed number of tests are carried from a package, the package is automatically changed to a new package and insertion of new yarn to the clamps is automatically done. A series of high resolution load cells enable testing of yarn with strength between 100 to $1000 \mathrm{cN}$. Software is provided for determining mean, maximum, minimum, S.D., CV, Confidence limits and a host of other useful information. A high resolution opto-electronic sensor measures the elongation of yarn. The tenacity of fiber is also dependent upon the following factors chain length of molecules in the fiber orientation of molecules size of the crystallites distribution of the crystallites gauge length used the rate of loading type of instrument used and atmospheric conditions.

The PET properties have been compiled for the $\mathrm{MTA}=10 \%$ and IV $=0.628$ and PTA $=100 \%$ and IV $=0.628$ ). The product-wise average results are as shown in Figs. 6, 7 and 8 . The viscosity of the polymer decreases considerably with increasing MTA blent $\%$ because the 4-CBA, metal ion content increases with MTA\%. The reason is 4-CBA cap the polymer chain, metal ions catalyze polymer degradation reaction. Because of these reasons intrinsic viscosity decrease, this reduces the draw force.

Average draw force, elongation and tenacity of pure PTA and 10\% MTA blend polyester yarn sample shown in Figs. 9 and 10 respectively. These graphs show that the relation between draw force and properties of the yarn follows same trend in both cases.

The above results show that with a 10\% MTA blends the draw force, tenacity and \% of elongation have slightly reduced. The reason is the chain length of polymer reduced with increasing MTA blend\%.

\section{Conclusion}

- Increasing the MTA percentage 4-carboxybenzaldehyde (4-CBA) is increase. It caps the polyester chain and limits molecular mass

- Draw force, Tensile strength and elongation properties decrease with increasing MTA\%. The reason is the chain length of polymer reduced with increasing MTA blend\%.

- FTIR analysis shows carboxyl group increases with MTA $\%$.

- DSC results shows MTA not effect on melting point.
Table 5 oligomer carboxylic end group dependence of esterifier temperature[2, 20]

\begin{tabular}{lll}
\hline MTA Blend \% & $\begin{array}{l}\text { Oligomer } \mathrm{COOH} \\
\text { group }(\mathrm{Meq} / \mathrm{Kg})\end{array}$ & Plant Parameter Changes \\
\hline 0 & 898 & Esterifier Temp-282.5 ${ }^{\circ} \mathrm{C}$, Level:62\% and thru through put-246TPD \\
10 & 886 & Esterifier Temp-278.75 ${ }^{\circ} \mathrm{C}$, Level:60\% and through put-234TPD \\
20 & 900 & Esterifier Temp-278.25 ${ }^{\circ} \mathrm{C}$, Level:59\% and through put-236TPD \\
\hline
\end{tabular}




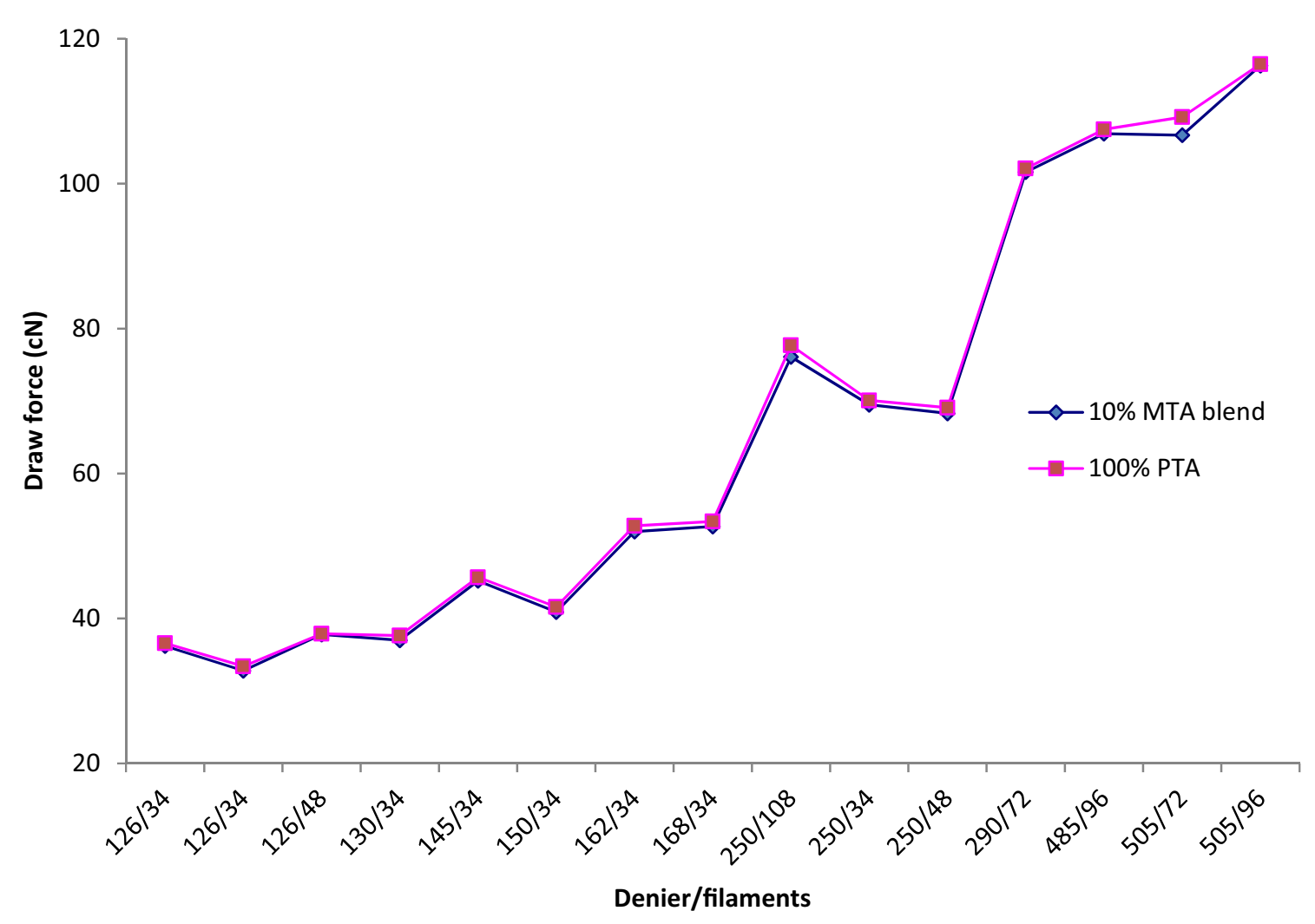

Fig. 6 Shows average draw force of pure PTA and 10\% MTA blend PET samples

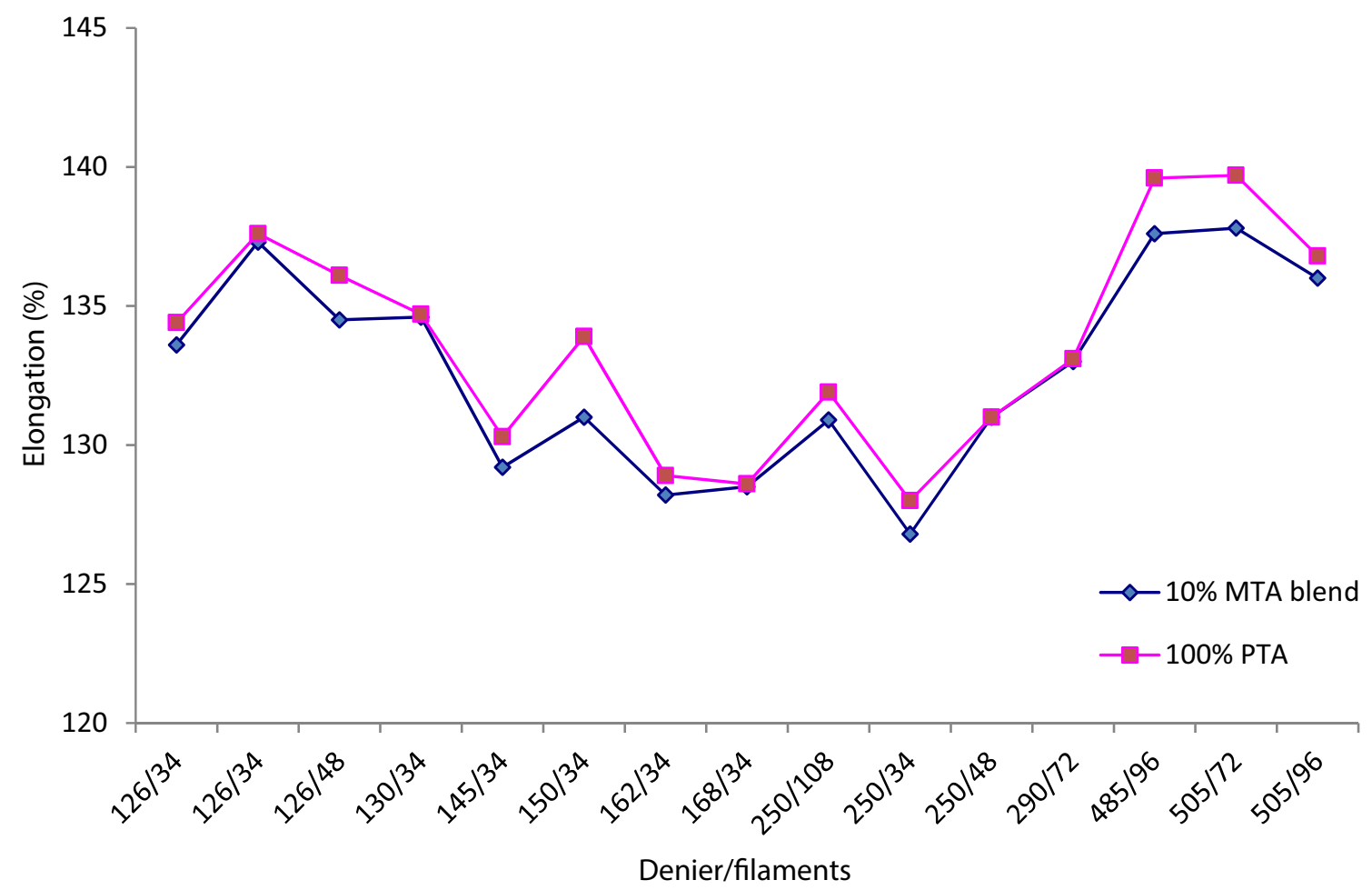

Fig. 7 Shows average elongation of pure PTA and 10\% MTA blend PET samples 


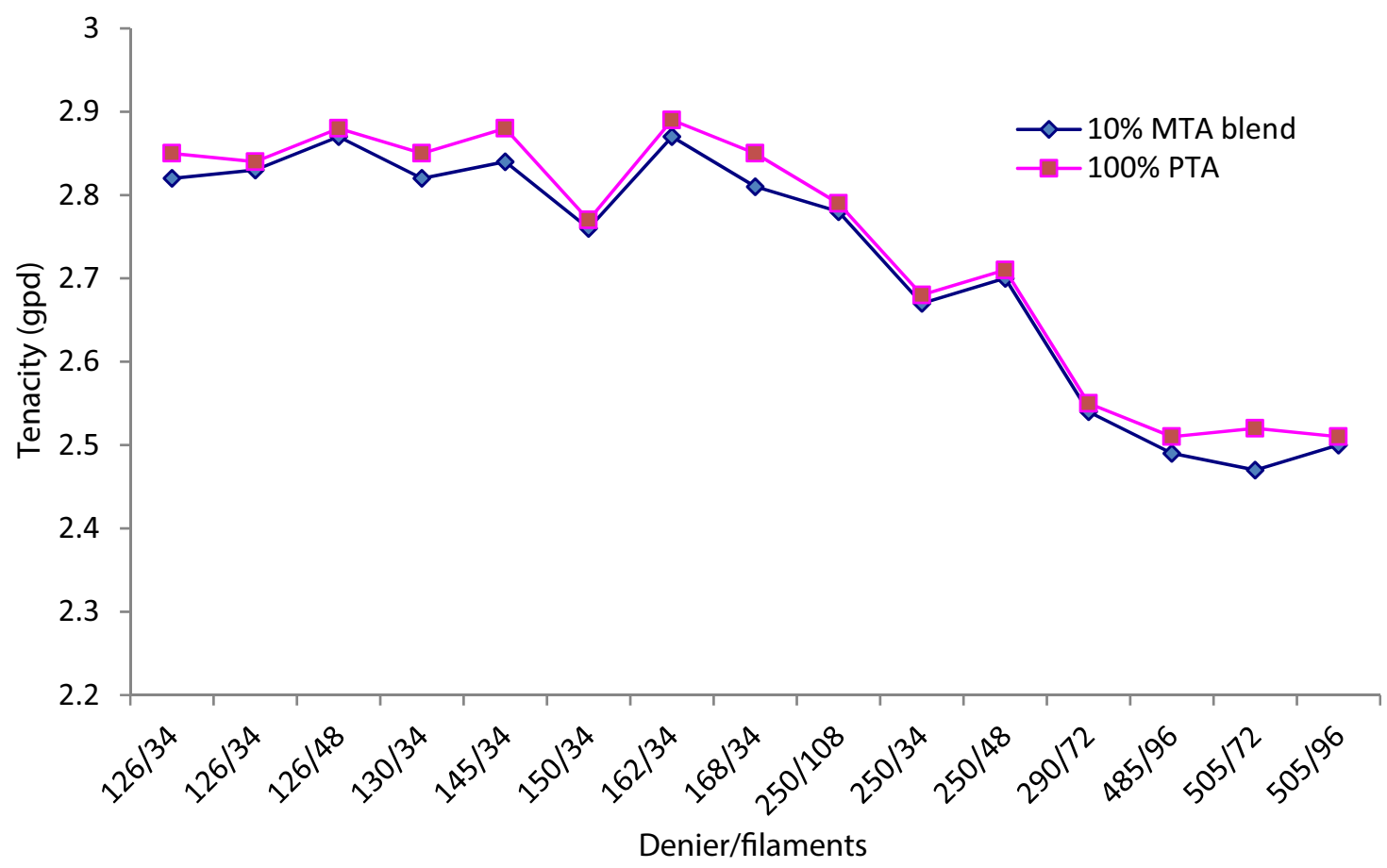

Fig. 8 Shows average tenacity of pure PTA and 10\% MTA blend PET samples

Table 6 Variation of physical properties of PET fibers with MTA blend at constant IV

\begin{tabular}{|c|c|c|c|c|c|c|}
\hline \multirow[t]{2}{*}{ Den/film } & \multicolumn{2}{|l|}{ Draw force $(\mathrm{cN})$} & \multicolumn{2}{|l|}{ Elongation (\%) } & \multicolumn{2}{|l|}{ Tenacity(gpd) } \\
\hline & 10\% MTA blend & $100 \%$ PTA & 10\% MTA blend & $100 \%$ PTA & $10 \%$ MTA blend & $100 \%$ PTA \\
\hline $126 / 34$ & 36.2 & 36.6 & 133.6 & 134.4 & 2.82 & 2.85 \\
\hline $126 / 34$ & 32.8 & 33.4 & 137.3 & 137.6 & 2.83 & 2.84 \\
\hline $126 / 48$ & 37.8 & 37.9 & 134.5 & 136.1 & 2.87 & 2.88 \\
\hline $130 / 34$ & 37 & 37.65 & 134.6 & 134.7 & 2.82 & 2.85 \\
\hline $145 / 34$ & 45.2 & 45.7 & 129.2 & 130.3 & 2.84 & 2.88 \\
\hline $150 / 34$ & 40.9 & 41.6 & 131.1 & 133.9 & 2.76 & 2.77 \\
\hline $162 / 34$ & 52 & 52.8 & 128.2 & 128.9 & 2.87 & 2.89 \\
\hline $168 / 34$ & 52.7 & 53.4 & 128.5 & 128.6 & 2.81 & 2.85 \\
\hline $250 / 108$ & 76.1 & 77.7 & 130.9 & 131.9 & 2.78 & 2.79 \\
\hline $250 / 34$ & 69.5 & 70.1 & 126.8 & 128 & 2.67 & 2.68 \\
\hline $250 / 48$ & 68.3 & 69.1 & 131 & 131 & 2.7 & 2.71 \\
\hline $290 / 72$ & 101.6 & 102.1 & 133 & 133.1 & 2.54 & 2.55 \\
\hline $485 / 96$ & 106.9 & 107.5 & 137.6 & 139.6 & 2.49 & 2.51 \\
\hline $505 / 72$ & 106.7 & 109.2 & 137.8 & 139.7 & 2.47 & 2.52 \\
\hline $505 / 96$ & 116.3 & 116.5 & 136 & 136.8 & 2.5 & 2.51 \\
\hline
\end{tabular}

- Chemically MTA is medium grade PTA having higher impurities.

- MTA like PTA forms Polyester with slight impact on product Quality.

- With respect to Particle Size and its distribution, the MTA is distinctly different from PTA. For this reason, present system of MTA feeding is not appropriate for homogeneous blending. The mixing of PTA and MTA should be done by using a separate Silo with a controlled feeding unit for MTA.

- At a particular MTA blend ratio, fine optimization of $\mathrm{CP}$ process parameter is required. So for process and product quality consistency, the blend ratio of MTA should be constant. 


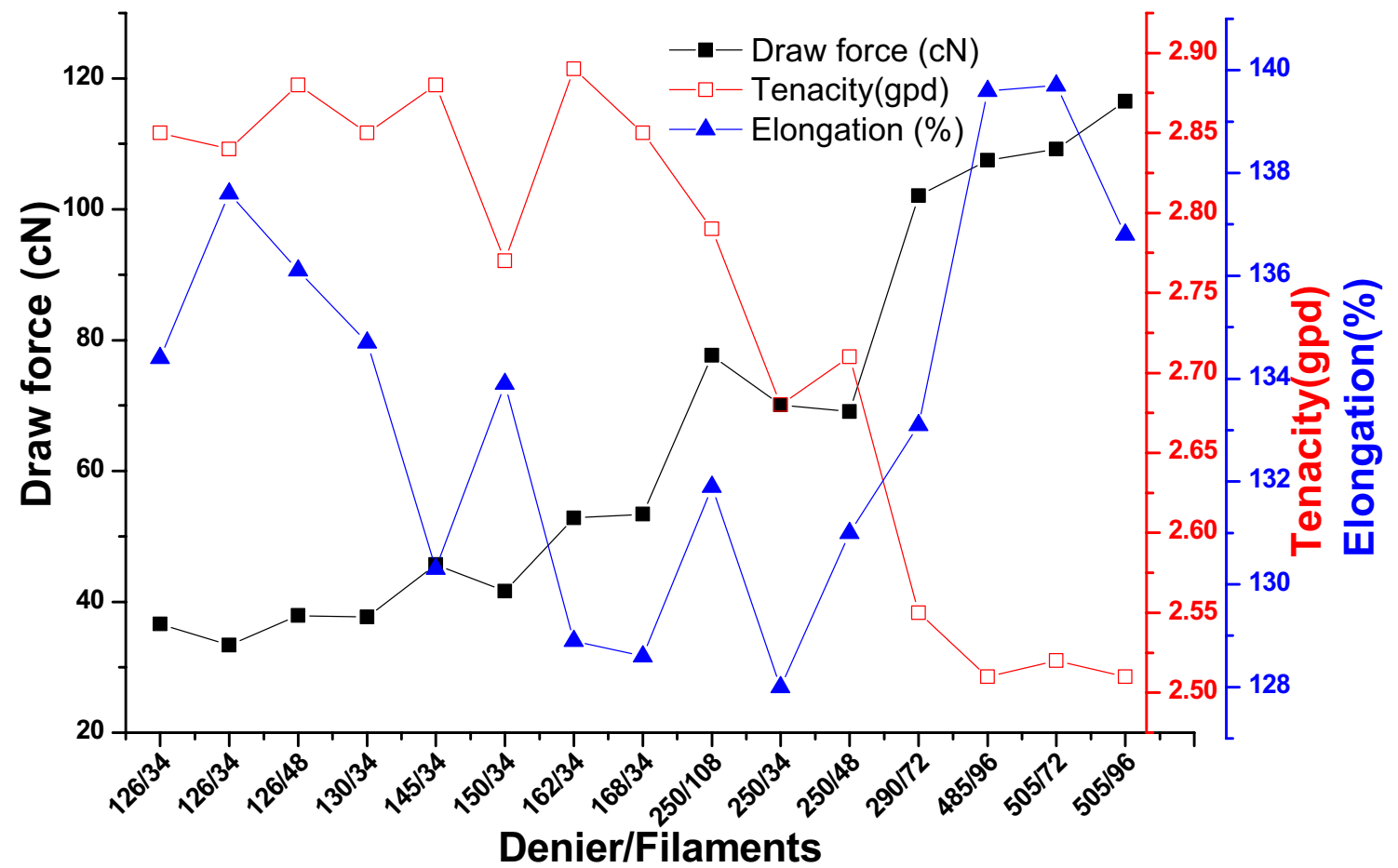

Fig. 9 Shows average draw force, tenacity and elongation of pure PTA polyester yarns

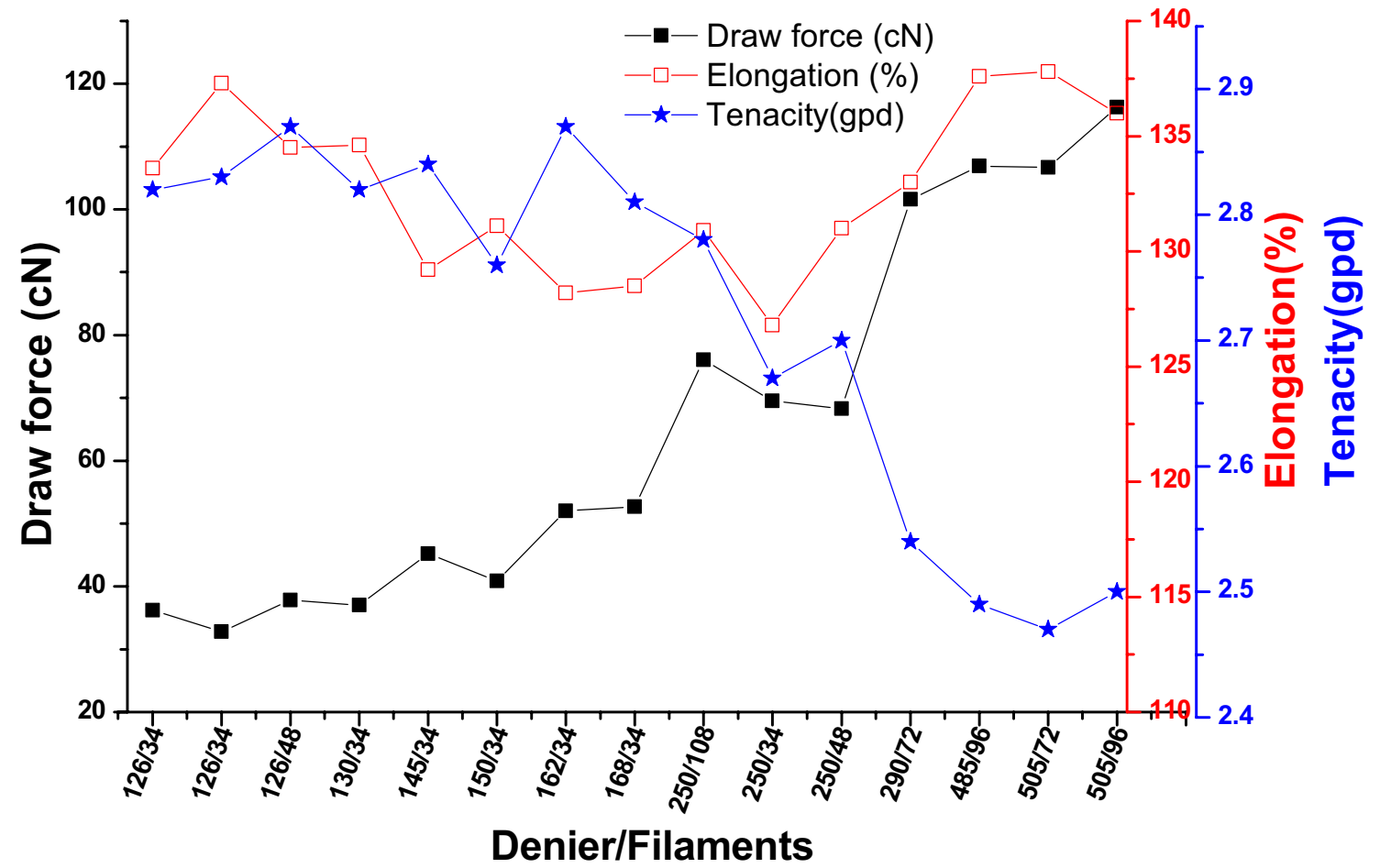

Fig. 10 Shows average draw force, tenacity and elongation of $10 \%$ MTA blend polyester yarns 
- With a 10-20\% MTA blend, the slight impact on product quality observed and the same is within the acceptable quality norm.

- Based on the above-detailed study and investigation, 10-20\% MTA may be blended with PTA within confirming product quality. With increasing competition and decreasing margin in Polyester business use of MTA in small proportion is a viable proposition looking into cost-benefit of MTA.

Acknowledgements Special thanks to Indo Rama Synthetics India Limited, Butibori, Maharashtra for providing some research facilities.

\section{Compliance with ethical standards}

Conflict of interest The Author(s) declare(s) that there is no conflict of interest.

Open Access This article is licensed under a Creative Commons Attribution 4.0 International License, which permits use, sharing, adaptation, distribution and reproduction in any medium or format, as long as you give appropriate credit to the original author(s) and the source, provide a link to the Creative Commons licence, and indicate if changes were made. The images or other third party material in this article are included in the article's Creative Commons licence, unless indicated otherwise in a credit line to the material. If material is not included in the article's Creative Commons licence and your intended use is not permitted by statutory regulation or exceeds the permitted use, you will need to obtain permission directly from the copyright holder. To view a copy of this licence, visit http://creativecommons .org/licenses/by/4.0/.

\section{References}

1. Mishra SP (2005) A text book of fibre science and technology, vol 233. New Age International Publisher. ISBN 81-224-1250-5

2. Mascia $L$ (1982) Thermoplastics materials engineering. Elsevier, London

3. Sheehan R (2000) Terephthalic Acid. Dimethyl Terephthalate, and Isophthalic Acid. https://doi.org/10.1002/14356007. a26 193

4. MTA: the key to PET cost advantage? https://www.icis.com/ explore/resources/news/2005/01/28/647563/mta-the-key-topet-cost-advantage-/

5. Medium-purity terephthalic acid production - cost analysis - TPA E11A, Intratec, 17-Sep-2019-Business and Economics
6. Gupta VB, Kothari VK (2012) Manufactured fibre technology. Chapman and Hall, London

7. van der Vegt AK, Govaert LE (2003) Polymeren: van keten tot kunststof, 5ed.DUP Blue Print, Delft. ISBN 90-407-2388-5.

8. Wang J, Yunus R, Li J, Li P, Zhang P, Kim J (2015) In situ synthesis of manganese oxides on polyester fiber for formaldehyde decomposition at room temperature. Appl Surface Sci 357:787794. https://doi.org/10.1016/j.apsusc.2015.09.109

9. López-Manchado MA, Arroyo M (2001) Effect of the incorporation of pet fibers on the properties of thermoplastic elastomer based on PP/elastomer blends. Polymer 42(15):6557-6563. https://doi.org/10.1016/S0032-3861(01)00127-6

10. Visakh PM, Morlanes MJM (2015) Polyethylene-based blends, composites and nanocomposites. Scrivener Publishing LLC, Rexford. https://doi.org/10.1002/9781118831328

11. Moraes MLL, Rubim JC, Realpozo RR, Marina FM (2004) Tavares, Analysis of impurities in crude and highly-purified terephthalic acid by capillary electrophoresis. J BrazChemSoc 15(3):400-406. https://doi.org/10.1590/S0103-50532004000300010

12. Garton A, Carlsson DJ, Wiles DM (1981) Infrared spectroscopy of polyethylene terephthalate fibers: uses and limitations. Textile Res J 51(1):28-34. https://doi.org/10.1177/004051758105100 106

13. Pereira AP, Silva MHPD, Tommasini F (2017) Processing and characterization of PET composites reinforced with geopolymer concrete waste. Materials Research 20:411-420. https:// doi.org/10.1590/1980-5373-mr-2017-0734

14. Record of Polyethylenterephthalat in the GESTIS Substance Database from the IFA

15. Young RJ, Lovell PA (1991) Introduction to polymers, 2nd edn. Chapman and Hall, London, p 285

16. Bhadeshia HKDH (2002) Thermal analyses techniques. differential thermal analysis. University of Cambridge, Material Science and Metallurgy. https://www.msm.cam.ac.uk/phase-trans/2002/ Thermal1.pdf

17. USP and Ep colour standard, Application note of hunter color lab, vol 8, 9. https://support.hunterlab.com/hc/en-us/article attachments/201371389/an20_08.pdf

18. Gupta VB, Kothari VK (2012) Manufactured fibre technology. Springer, Berlin, pp 68-78

19. Bunsell AR (2018) Handbook of Properties of Textile and Technical Fibres: A volume in The Textile Institute Book Series, 2nd ed. Woodhead Publishing, Sawston, pp 17-34

20. Hu SW, Myung HS, Bae JS et al (2000) Synthesis and crystallization behaviors of modified PET copolymers. Fibers Polym 1:76-82. https://doi.org/10.1007/BF02875189

Publisher's Note Springer Nature remains neutral with regard to jurisdictional claims in published maps and institutional affiliations. 